\title{
Protective and Suppressing Electromagnetic Interference Properties of Epoxy Coatings Containing Nano-Sized NiZn Ferrites
}

\author{
Andrzej Miszczyk* \\ Department of Electrochemistry, Corrosion and Materials Engineering, Faculty of Chemistry, The Gdansk University of \\ Technology, Gdansk, Poland
}

Nano-crystalline ferrites with the chemical formula $\mathrm{Ni}_{x} \mathrm{Zn}_{(1-x)} \mathrm{Fe}_{2} \mathrm{O}_{4}$, where $x=0,0.2$, $0.4,0.6,0.8,1.0$, were synthesized using a co-precipitation method. The obtained ferrites were investigated by X-ray diffraction (XRD). The corrosion inhibiting behavior of nano-sized ferrites was tested using carbon steel samples and $10 \%$ aqueous ferrite extracts. Results were compared with previous data obtained for micro-sized ceramic ferrites. Nanoparticles show more favorable properties regarding inhibiting corrosion processes on steel. Two Millimeter thick epoxy coatings on steel containing $10 \%$ vol. of nano-sized ferrites has been investigated as a microwave absorber. The microwave reflectivity of the coating was measured within the range from 6.5 to $15 \mathrm{GHz}$. Both the nano- and micro-sized ferrites included in the coatings exhibited

OPEN ACCESS

Edited by:

Michele Fedel,

University of Trento, Italy

Reviewed by:

Wan Jeffrey Basirun,

University of Malaya, Malaysia Da-Hai Xia,

Tianjin University, China

*Correspondence: Andrzej Miszczyk andrzej.miszczyk@pg.edu.pl

Specialty section:

This article was submitted to Environmental Materials,

a section of the journal

Frontiers in Materials

Received: 01 August 2019 Accepted: 19 May 2020

Published: 23 June 2020

Citation:

Miszczyk A (2020) Protective and

Suppressing Electromagnetic Interference Properties of Epoxy

Coatings Containing Nano-Sized NiZn

Ferrites. Front. Mater. 7:183.

doi: 10.3389/fmats.2020.00183 different reflection loss spectra. The greatest attenuation on a level of 8-16 dB was observed. The nano-ferrite-filled epoxy coating exhibited a higher minimum reflection frequency in comparison with the micro-ferrite-filled coating. A frequency shift of 1-2 $\mathrm{GHz}$ was observed.

Keywords: corrosion, pigment, NiZn ferrites, microwave absorption, EMI

\section{INTRODUCTION}

After the withdrawal of effective anti-corrosive but toxic pigments, it is necessary to introduce new non-toxic pigments in protective coatings. An interesting and desirable option is to use for this purpose materials that in addition to anti-corrosion properties show other useful properties. Materials that meet these expectations include ferrites. In addition to anti-corrosive properties, they have the ability to suppress electromagnetic waves. This is important now due to the presence of so-called electromagnetic smog in the environment and the problems of electromagnetic interference.

Electromagnetic interference (EMI) is an issue which happens with electric or electronic devices when the operation of a device is disturbed, interrupted or degraded by any undesirable, natural or artificial in origin, electromagnetic radiation. Any electronic device can potentially create electromagnetic interference. The increasing number of electronic systems and the use of microwaves in both civil and military fields have resulted in a growth in EMI (Weston, 2001; Zeddam et al., 2009; Kharissova et al., 2015; Koysuka, 2019; Suarez et al., 2019). This kind of pollution can lead to serious disturbance or damage to electronic equipment. Human health aspects are also of importance (Paniagua et al., 2009). Microwaves can interact with the biosystem causing diverse physiological impacts (Banik et al., 2003; Breckenkamp et al., 2003). One practical approach for EMI shielding relies on the use of microwave absorber. In addition, there has been 
the development of stealth technologies for reducing the radar cross-section (RCS). These work by absorption of the electromagnetic radar signal by a coating material applied on the surface of the target (Vinoy and Jha, 1996). This kind of camouflage of military objects is of great interest today when radar technology has reached a high level of excellence.

A range of materials which act as electromagnetic wave absorbers has been developed (Nicolaescu, 2006; Duan and Guan, 2017; Koysuka, 2019). For significant attenuation, the absorber material ought to possess electric and magnetic dipoles which will interact with the electromagnetic field of the radiation (Simms and Fusco, 2005; Landy et al., 2008; Wang et al., 2009). In this way, it attenuates radiated electromagnetic energy and transforms it to heat. Composite coatings filled with magnetic ferrites reduce the radiation caused by the use of electromagnetic sources in the environment and can be used to protect electronic devices against external unwanted electromagnetic fields. Therefore they have been recently investigated in many studies that concentrate on their microwave absorbing properties (Yusoffa and Abdullah, 2004; Dosoudil et al., 2006; Abbas et al., 2007; Bueno et al., 2008; Zhao et al., 2009; Kharissova et al., 2015; Grigoriev et al., 2016; Suarez et al., 2019). The properties of ferrite composite materials obtained by mixing ferrite particles with a resin can also be partially controlled by processing conditions. The conducted investigations have been concerned with particular materials and specific preparation methods.

A ferrite is usually described by the general chemical formula $\mathrm{MFe}_{2} \mathrm{O}_{4}$, where $\mathrm{M}$ represents a metal in a bivalent state, e.g., $\mathrm{Fe}^{2+}, \mathrm{Zn}^{2+}, \mathrm{Ni}^{2+}, \mathrm{Co}^{2+}, \mathrm{Mn}^{2+}, \mathrm{Cu}^{2+}$ (Miszczyk and Darowicki, 2011). Depending on the type of metal, magnetic (e.g., $\mathrm{Fe}^{2+}, \mathrm{Ni}^{2+}, \mathrm{Co}^{2+}, \mathrm{Mn}^{2+}$ ) or non-magnetic (e.g., $\mathrm{Zn}^{2+}$, $\mathrm{Ca}^{2+}, \mathrm{Cu}^{2+}$ ) ferrites may be obtained. They show typically high chemical stability, high magnetic loss and high resistivity. In general, studies show that ferrites behave in different coating formulations as active anti-corrosive pigments (Sekine and Kato, 1986; Abu Ayana et al., 1997; Kalendova, 2000; Zubielewicz and Gnot, 2004; Kalendova and Vesely, 2008; Miszczyk and Darowicki, 2011). They passivate the metal substrate, forming an insoluble, protective layer of hydroxides of metals contained in ferrite pigment. This effect is promoted by creating an alkaline environment in cathode areas at the interface between the coating and the substrate. In addition, ferrite pigments can also form inhibitive zinc soaps in certain binders (Kalendova, 2000).

Recently great attention has been paid to nano-sized ferrites (Poddar et al., 2009; Priyadharsinia et al., 2009; Vermaa et al., 2009; Vinas et al., 2015; Kefeni et al., 2017; Sarkar et al., 2018). Also in the field of coating protection, the use of nanoparticles as active pigments in protective coatings seems potentially promising. Nanoparticles have a much larger active surface, so they can be used with a much smaller amount (Shi et al., 2019). They can also be located much closer to the protected area, which can increase their effectiveness. The significant properties of ferrites change as the size of the particles turns into the nanometric magnitude (Awschalom and Vincenzo, 1995; Shi et al., 1996; Chen and Zhang, 1998; Hernando, 1999; Kodama and Berkowitz, 1999; Ehrhardt et al., 2002; Shenoy et al., 2004; Andrade et al., 2009). There are several methods of preparation of nano-sized ferrite particles including auto-combustion (Sileo et al., 2002), hydrothermal synthesis (Dias et al., 1997), mechanochemical synthesis (Shi et al., 2000), co-precipitation followed by calcination (Abraham, 1994), sol-gel processes (Pradeep et al., 2008), etc. Among these processes, co-precipitation has been shown to be an easy and promising technique for the preparation of nano-sized ferrite particles.

The anticorrosive properties of some micro- and nano-sized ferrite pigments have been documented (Sekine and Kato, 1986; Abu Ayana et al., 1997; Kalendova, 2000; Zubielewicz and Gnot, 2004; Kalendova and Vesely, 2008; Miszczyk and Darowicki, 2011; Chaudhry et al., 2015, 2017; Grigoriev et al., 2016). Although conventional anticorrosive pigments containing lead or hexavalent chromium (VI) (zinc chromate) cannot be used formally these days due to the environmental and human hazard, there is still a need for effective active anti-corrosive pigments. Non-toxic ferrites may be the answer to this demand. Therefore, they are used as drug carriers in order to target specific sites in the human body (Rana et al., 2007). The concomitant anticorrosive and microwave absorption properties of these pigments offer functionalities not found in traditional coatings and it makes them attractive as an additive to multifunctional protective coatings (Miszczyk and Darowicki, 2011).

In this work, epoxy-NiZn ferrite composites prepared by use of conventional ceramic (micro-sized polycrystalline structure) and the aqueous precipitation (nano-crystalline structure) followed by calcination methods were investigated. The anticorrosive and microwave absorbing properties of epoxy composites containing obtained ferrites were compared experimentally.

\section{MATERIALS AND METHODS}

Ferrites with the chemical formula $\mathrm{Ni}_{\mathrm{x}} \mathrm{Zn}_{(1-\mathrm{x})} \mathrm{Fe}_{2} \mathrm{O}_{4}(x=0$, $0.2,0.4,0.6,0.8,1.0)$ were synthesized by using traditional ceramic (Miszczyk and Darowicki, 2011) and aqueous coprecipitation methods.

The ferrite was prepared in micro-sized form by heating thoroughly mixed powders of nitrates $\mathrm{Fe}\left(\mathrm{NO}_{3}\right)_{3} \cdot 9 \mathrm{H}_{2} \mathrm{O}$, $\mathrm{Zn}\left(\mathrm{NO}_{3}\right)_{3} \cdot 6 \mathrm{H}_{2} \mathrm{O}$ and $\mathrm{Ni}\left(\mathrm{NO}_{3}\right)_{3} \cdot 6 \mathrm{H}_{2} \mathrm{O}$ of reagent grade purity (min. 99\%) at $1200^{\circ} \mathrm{C}$ at ambient atmosphere for $2 \mathrm{~h}$ and later natural cooling after switching off the oven. Ferrite powders were later processed by mechanical grinding of sintered ferrite during ca. $5 \mathrm{~h}$ in a ball mill, followed by washing with water and drying at $80^{\circ} \mathrm{C}$ for $24 \mathrm{~h}$ (Miszczyk and Darowicki, 2011).

The ferrite in nano-sized form was prepared by the coprecipitation method. The starting materials were the same reagent grade purity nitrates $\mathrm{Fe}\left(\mathrm{NO}_{3}\right)_{3} \cdot 9 \mathrm{H}_{2} \mathrm{O}, \mathrm{Zn}\left(\mathrm{NO}_{3}\right)_{3} \cdot 6 \mathrm{H}_{2} \mathrm{O}$ and $\mathrm{Ni}\left(\mathrm{NO}_{3}\right)_{3} \cdot 6 \mathrm{H}_{2} \mathrm{O}$. Desired amounts of $\mathrm{Fe}\left(\mathrm{NO}_{3}\right)_{3} \cdot 9 \mathrm{H}_{2} \mathrm{O}$, $\mathrm{Zn}\left(\mathrm{NO}_{3}\right)_{3} \cdot 6 \mathrm{H}_{2} \mathrm{O}$ and $\mathrm{Ni}\left(\mathrm{NO}_{3}\right)_{3} \cdot 6 \mathrm{H}_{2} \mathrm{O}$ were mixed to yield a clear aqueous solution. The mixed solution was placed in a water bath at $90^{\circ} \mathrm{C}$, and then $\mathrm{NaOH}$ solution $(6 \mathrm{~mol} / \mathrm{l})$ was added dropwise with intensive stirring. During the precipitation, the reaction solution was vigorously stirred with a magnetic stirrer. After reaction completion, the precipitates were kept stirred in the reaction solution for $2 \mathrm{~h}$ at a temperature of 
$90^{\circ} \mathrm{C}$. The co-precipitated powders were filtered and washed with deionized water many times, followed by washing with ethyl alcohol and filtering. The washed powders were dried at $80^{\circ} \mathrm{C}$ during $24 \mathrm{~h}$. Density and oil number were determined in order to obtain the proper formulation of the composite. For comparison, $\mathrm{Fe}_{2} \mathrm{O}_{3}$ nanoparticles were also synthesized via a co-precipitation method using iron chloride hexahydrate $\left(\mathrm{FeCl}_{3}\right.$ $\left.6 \mathrm{H}_{2} \mathrm{O}\right)$ as a precursor.

The precipitates were calcined at $300,400,500$, and $600^{\circ} \mathrm{C}$ for $2 \mathrm{~h}$ and ground in a ball-mill for $5 \mathrm{~h}$. After analysis of the XRD pattern, only the powder calcined at $600^{\circ} \mathrm{C}$ was afterwards tested. XRD analysis was performed on a Philips X'Pert diffractometer with $\mathrm{Cu} \mathrm{K}_{\alpha}$ radiation in the $2 \Theta$ range from $10^{\circ}$ to $80^{\circ}$ by steps of $0.02^{\circ}$. The identification of compounds was conducted using the ICDD database.

Composite materials have been prepared by mixing ferrite particles with an epoxy resin (Epidian-5, from Sarzyna-Organika Chemical Company in Nowa Sarzyna, Poland, clear epoxy resin with molecular mass $\leq 700 \mathrm{u}$, diglicidyl ether of bisphenol A) using stirrer during $1 \mathrm{~h}$ (800 turns per min). After that, a proper amount of hardener (Z1 from Sarzyna-Organika Chemical Company in Nowa Sarzyna, Poland, triethylenetetramine) was added. Composites containing $10 \%$ vol of ferrites were prepared on a low carbon steel substrate (Q-panel). The thickness of all coatings was $2 \mathrm{~mm}$, which was arbitrarily chosen.

In order to measure microwave absorption properties of the prepared coatings, the reflection coefficients were determined by using Site Master ${ }^{\mathrm{TM}}$ (Anritsu) S820D and WR90 waveguide connected by APC-7 mm coaxial line. Measurements were made in the $6.5-15 \mathrm{GHz}$ range by collecting 256 frequency points using the reflection method (Chen et al., 2004). Before the experiments, the set-up was calibrated using three standards, which are required to eliminate the directivity, reflection tracking and source match errors. 1/8, 3/8 offset shorts and termination were used.

In order to assess the properties of nano-ferrites as corrosion inhibitors, electrochemical tests of carbon steel in 10\% aqueous extracts from nano-pigments, obtained after 2 weeks, were performed. The electrochemical cell consisted of the carbon steel (S235JR) sample with an area of $1 \mathrm{~cm}^{2}$, as a working electrode, saturated calomel electrode (SCE) as a reference electrode, and a platinum mesh as a counter electrode. Electrochemical measurements were made using ModuLab XM ECS (Solartron Analytical-Ametek SI, USA). Polarization tests were carried out with the scan rate of $10 \mathrm{mV} / \mathrm{s}$ and potential range of $-150 \mathrm{mV}$ to $+600 \mathrm{mV}$ with respect to open circuit potential (OCP).

AFM studies were conducted by means of an AFM device Ntegra Prima (NT-MDT, Russian Federation) supplemented with a magnetic tip. In this case, the magnetic forces, acting on a magnetized tip by the sample, are measured and local magnetic properties of the surface in the form of a map were registered.

\section{RESULTS AND DISCUSSION}

Characterization of the obtained ferrite samples was carried out by X-ray diffraction (XRD) analysis of powders. Figure $\mathbf{1}$ shows as an example the XRD patterns of the as-precipitated powder of nickel ferrite and after being calcined at 300, 400, 500, and $600^{\circ} \mathrm{C}$. The as-precipitate and calcined at 300 and $400^{\circ} \mathrm{C}$ powders were amorphous. They show broad and unresolved peaks. The $\mathrm{XRD}$ patterns of powders calcined at 500 and $600^{\circ} \mathrm{C}$ show a clear pattern, which corresponds to the known structure of a spinel-type lattice of ferrite. All of the peaks indicated that the obtained ferrite is $\mathrm{NiFe}_{2} \mathrm{O}_{4}$. Their position agrees with the standard pattern presented in Figure $\mathbf{1}$ based on the International Center for Diffraction Data (ICDD)-Powder Diffraction File (data set 44-1485). Apart from the most intense peak located at the diffraction angle of $2 \theta=35.691^{\circ}$, corresponding to the (311) reflection plane, other peaks are located at $2 \theta=30.301^{\circ}, 37.331^{\circ}$, $43.381^{\circ}, 53.831^{\circ}, 57.381^{\circ}, 62.021^{\circ}$ and $74.581^{\circ}$.
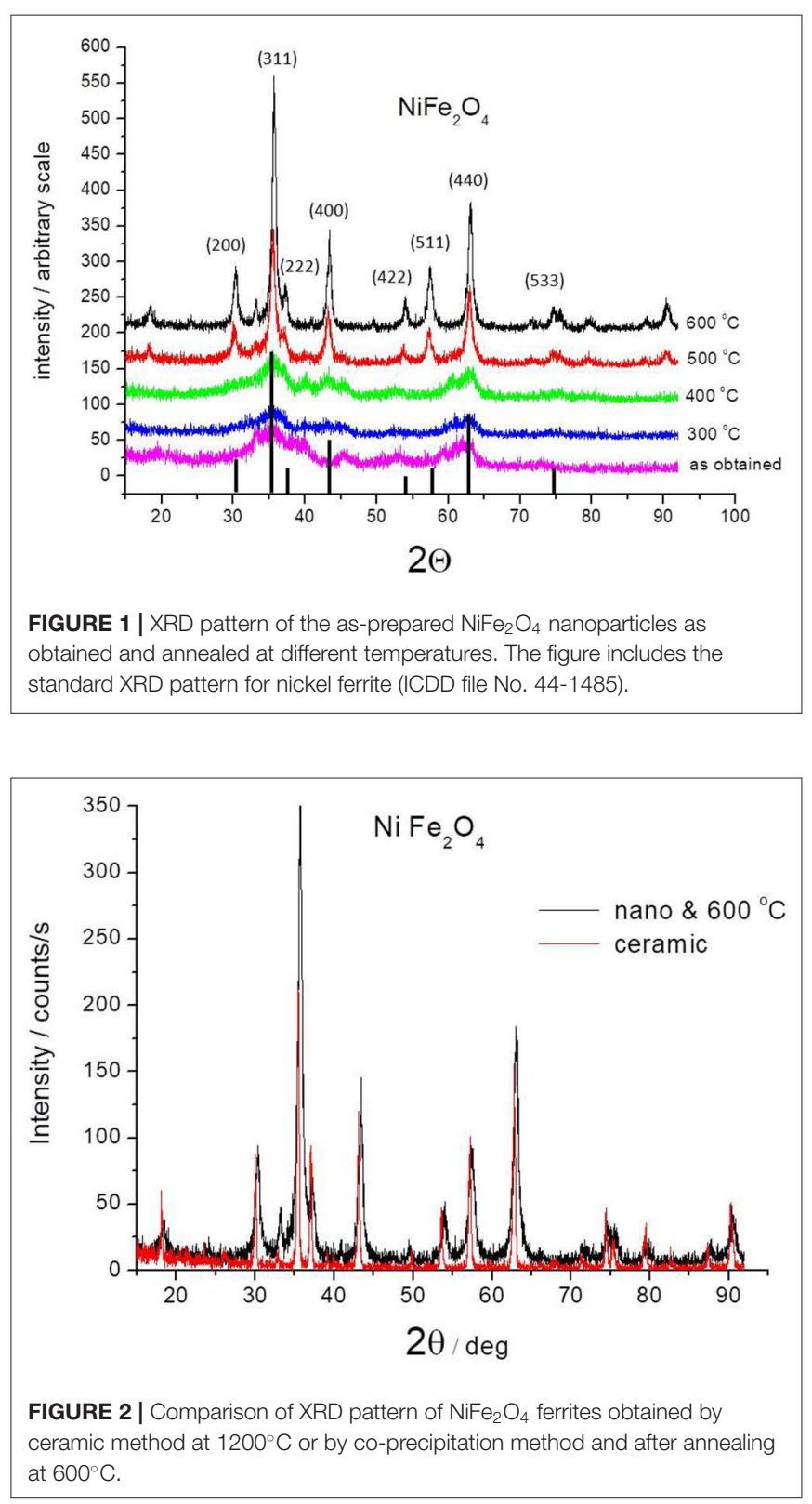
Figure 2 shows a comparison of the XRD pattern of the ceramic ferrite (calcined at $1200^{\circ} \mathrm{C}$ ) with the same one obtained by co-precipitation method and calcined at $600^{\circ} \mathrm{C}$. There are no essential differences between them in relation to the position of the peaks. There are differences in peak widths that result from the size of the crystallites. Ceramic ferrites are sharper due to larger crystallite sizes. This indicates that particles with significantly smaller crystallite sizes were obtained using the codeposition method. The results for ferrite with nano-crystalline structure presented below refer to powder obtained by the coprecipitation method and followed by calcination at $600^{\circ} \mathrm{C}$.

Figure 3 shows XRD patterns for all nano-crystalline ferrites obtained by the co-precipitation method and followed by calcination at $600^{\circ} \mathrm{C}$. It also includes a standard nickel ferrite pattern based on ICDD data for comparison. All samples exhibit a single phase with a spinel structure. The average grain size $(D)$ of ferrites was calculated from the diffraction

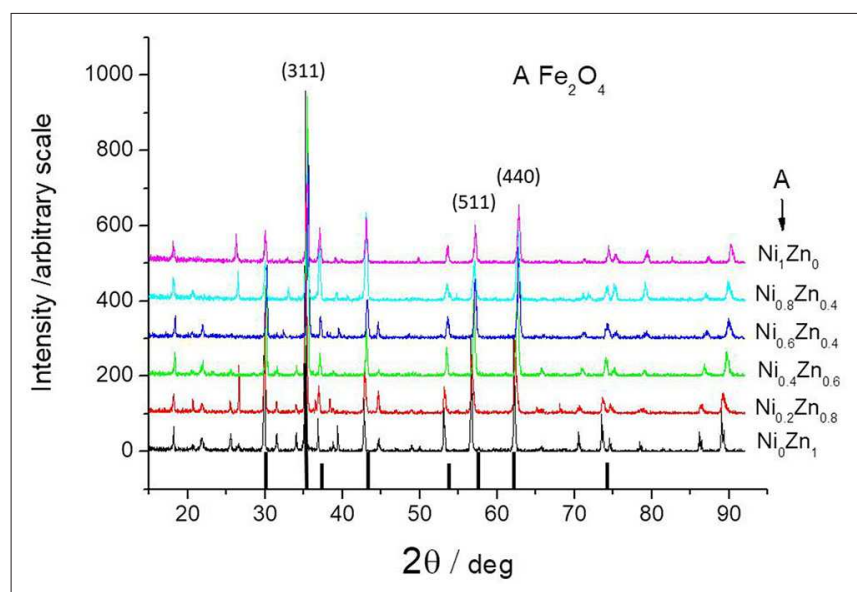

FIGURE 3 | XRD pattern of all ferrites obtained by co-precipitation method and followed by annealing at $600^{\circ} \mathrm{C}$. The figure includes the standard XRD pattern for nickel ferrite (ICDD file No. 44-1485). peak of the (311) plane using the Debye-Scherrer formula (Armstrong and Karceff, 1999):

$$
D=0.9 \lambda /(\beta \cos \theta)
$$

where $\lambda$ is the $\mathrm{X}$-ray wavelength, $\beta$ is the half-maximum breath and $\theta$ is the Bragg angle of the (311) plane. According to the obtained data and formula (1), the average particle size of the nano-crystalline NiZn ferrites is found to be ca. $20 \mathrm{~nm}$. The individual particles of the poly-crystalline ferrites were typically $120-180 \mathrm{~nm}$ in diameter.

In order to verify the size of particles obtained by codeposition, AFM measurements of the composite cross-section containing these particles were performed. Utilizing the magnetic properties of ferrite particles, a magnetic tip was also used. Figure 4 shows the obtained diagrams. The classic AFM technique does not allow for clear observation of nanoparticles embedded in the epoxy binder. The application of the tip covered with a magnetic layer causes that the phase of the tip oscillations changes when it interacts with the magnetic area. This causes a phase shift recorded in the image (the unit on the vertical axis in Figure 4B is degree). Figure 4 demonstrates (light areas in Figure 4A and dark areas in Figure 4B) that the particle sizes do not exceed several hundred $\mathrm{nm}$ and that they are most likely the result of the agglomeration of individual crystallites. This phenomenon is typical for such particles if no special surface treatment has been performed (Kefeni et al., 2017).

The microwave absorption property was presented using microwave loss efficiency. Figures 5-10 show the reflection loss of composites containing the investigated ferrites. Each figure compares composites filled by poly-crystalline (ceramic) and nano-crystalline ferrites. The reflection loss $\left(R_{L}\right)$ is given by the difference between the incident and reflected signal level expressed in logarithmic scale according to the equation (Chen et al., 2004):

$$
R_{L}(d B)=10 \log \left(P_{r} / P_{o}\right)
$$
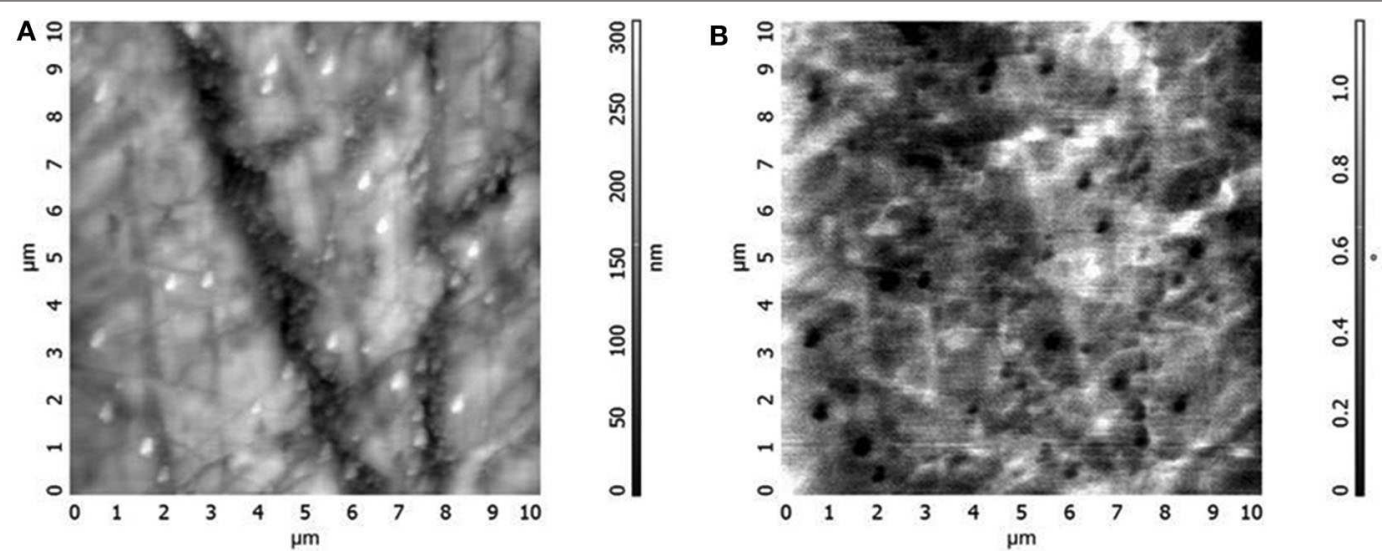

FIGURE 4 | AFM images of topography (A) and magnetic properties (B) on the cross-section of the epoxy coating containing nano-sized nickel ferrite. 


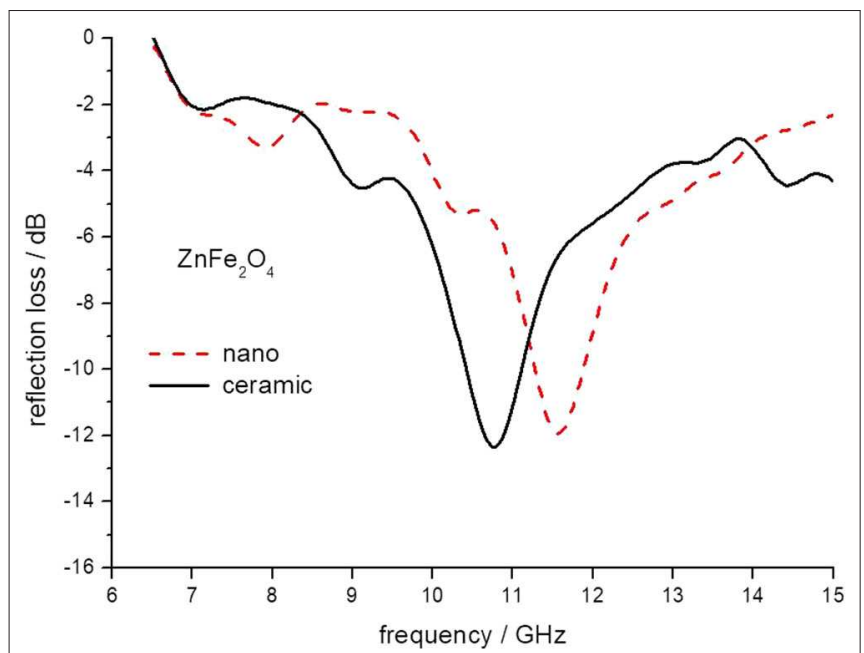

FIGURE 5 | The reflection loss of epoxy composite containing ceramic and nanoparticles of $\mathrm{ZnFe}_{2} \mathrm{O}_{4}$ ferrites.

where: $P_{r}$-the power of the reflected wave,

$P_{o}$-the power of the incident wave.

Based on transmission line theory, the reflection loss $\left(R_{L}\right)$ for a single layer absorbing material backed by a conductor is given by

$$
R_{L}=20 \log \left|\left(Z_{\text {in }}-Z_{0}\right) /\left(Z_{\text {in }}+Z_{0}\right)\right|
$$

where: $Z_{0}=\sqrt{\frac{\mu_{0}}{\varepsilon_{0}}}$ is the impedance of free space and the input impedance $\left(\mathrm{Z}_{\mathrm{in}}\right)$ at the air-material interface is given by

$$
Z_{\text {in }}=Z_{0} \sqrt{\frac{\mu_{0}}{\varepsilon_{0}}} \tanh \left[j(2 \pi f d / c) \sqrt{\frac{\mu_{r}}{\varepsilon_{r}}}\right]
$$

where $\varepsilon_{0}$ is the dielectric constant of free space, $\varepsilon_{r}=\varepsilon^{\prime}-\mathrm{j} \varepsilon^{\prime}$ is the complex permittivity, $\mu_{0}$ is the permeability of free space, $\mu_{r}$ $=\mu^{\prime}-\mathrm{j} \mu^{\prime \prime}$ is the complex permeability, $f$ is the frequency of the incident wave, $c$ is the velocity of light in free space and $d$ is the thickness of absorber. The imaginary unit is denoted by $j$.

There are two conditions to achieve low $R_{L}$ values:

a) the incident wave should transmit from the air (free space) into the materials with minimum reflection,

b) a material should attenuate the absorbed wave.

In order to implement the first condition, impedance matching between the material surface and free space is required. The second condition requires that the energy of electromagnetic waves inside material transform into other forms of energy, e.g., heat. In this case, specific high magnetic and electrical loss properties of the material are required. Electromagnetic waves supply energy to material by means of electric and magnetic fields. These fields can exert forces and carry charges and magnet moments in the material.

Electromagnetic wave energy can be absorbed and dissipated to heat through magnetic and dielectric losses (Equations 3,

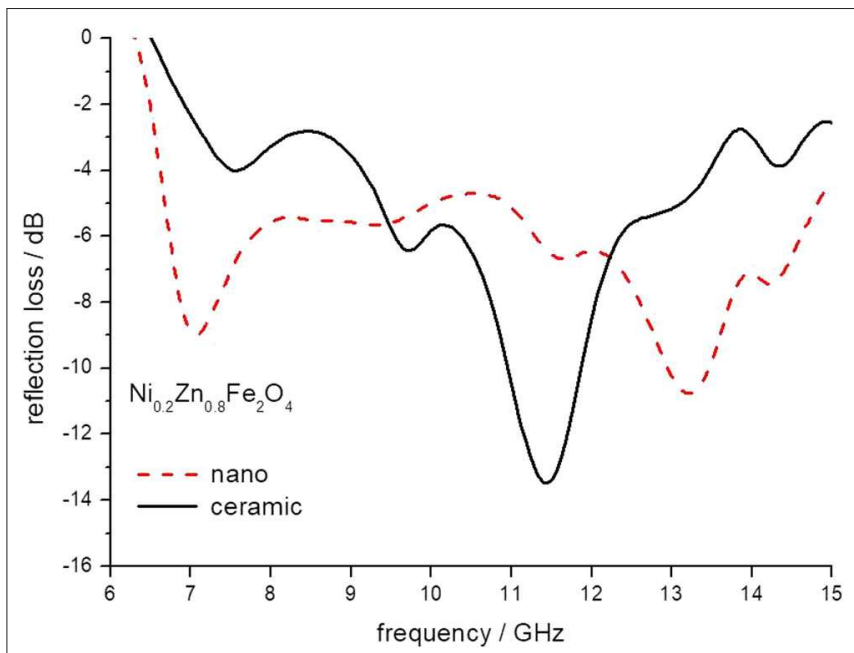

FIGURE 6 | The reflection loss of epoxy composite containing ceramic and nanoparticles of $\mathrm{Ni}_{0.2} \mathrm{Zn}{ }_{0.8} \mathrm{Fe}_{2} \mathrm{O}_{4}$ ferrites.

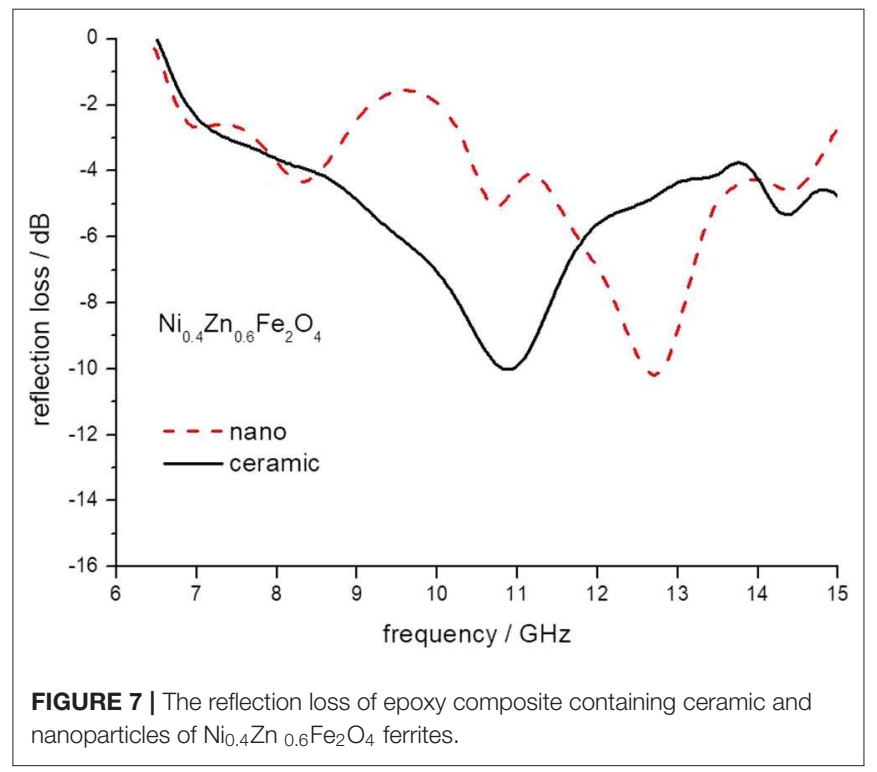

4). This can be quantified by reflection loss (Equation 2). The minimum value of the reflection loss shows the frequency of the wave, which has the highest attenuation. It means maximum absorption of the microwave power for a particular sample thickness.

The minimum of reflection loss for each ferrite composite is presented in Figure 11 as a function of the content of nickel in ferrite. It seems that both micro- and nano-sized ferrites containing the composite exhibit much the same values of attenuation, except nickel ferrite. However, there is a clear shift in the frequency of maximum attenuation, Figure 12. Composites containing nano-ferrites exhibit a higher frequency of maximum attenuation. Probably, it is related to the domains' wall mobility at a lower frequency. The resonance frequency $f$ is 


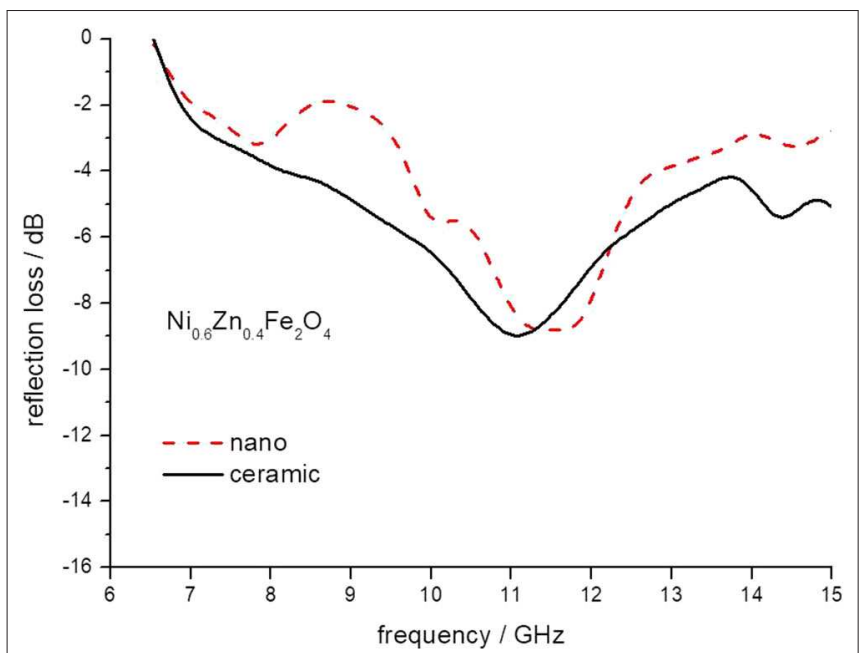

FIGURE 8 | The reflection loss of epoxy composite containing ceramic and nanoparticles of $\mathrm{Ni}_{0.6} \mathrm{Zn}{ }_{0.4} \mathrm{Fe}_{2} \mathrm{O}_{4}$ ferrites.

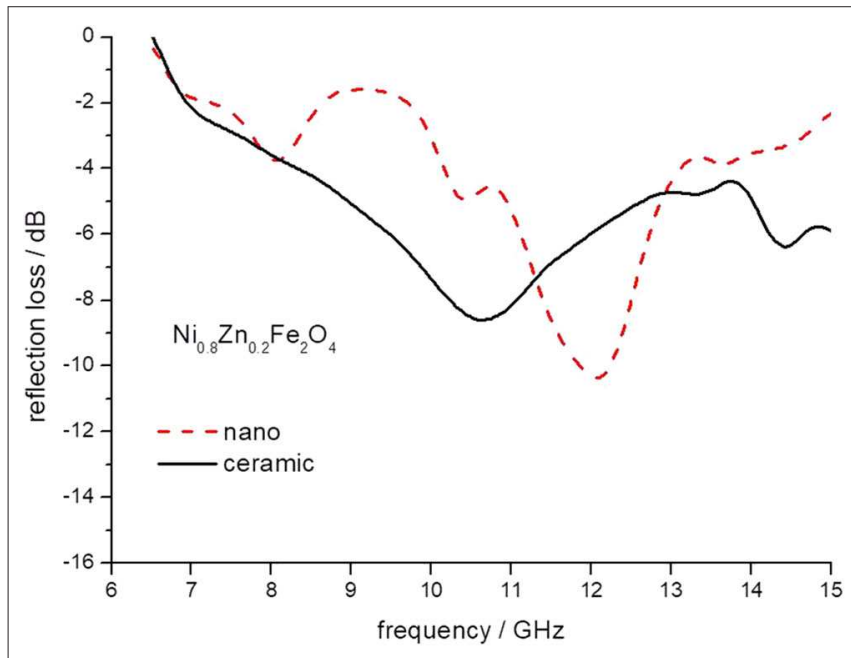

FIGURE 9 | The reflection loss of epoxy composite containing ceramic and nanoparticles of $\mathrm{Ni}_{0.8} \mathrm{Zn} 0.2 \mathrm{Fe}_{2} \mathrm{O}_{4}$ ferrites.

proportional to the anisotropy field $H_{a}$ according to the equation (Chikazumi, 1997):

$$
f=(\gamma / 2 \pi) H_{a}
$$

where: $\gamma$ is gyromagnetic ratio,

$H_{a}$ is crystal anisotropy field.

These results suggest an increase in the crystal anisotropy field in nano-sized ferrites as compared to micro-sized ferrites. It seems that there is certain intrinsic randomness with regard to size and orientation of the nanostructures and this depends on the preparation technique used and can be specific for a particular method of preparation.

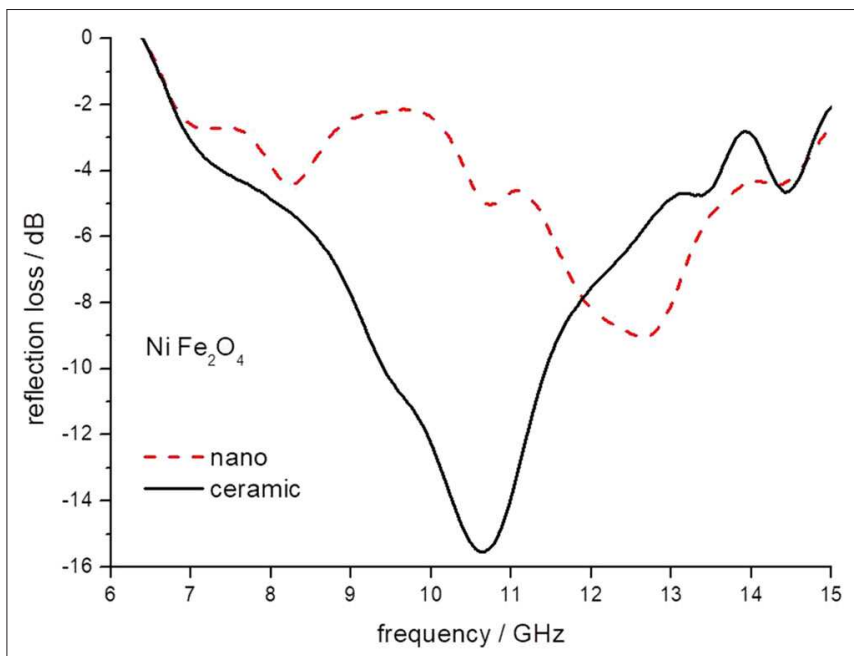

FIGURE 10 | The reflection loss of epoxy composite containing ceramic and nanoparticles of $\mathrm{NiFe}_{2} \mathrm{O}_{4}$ ferrites.

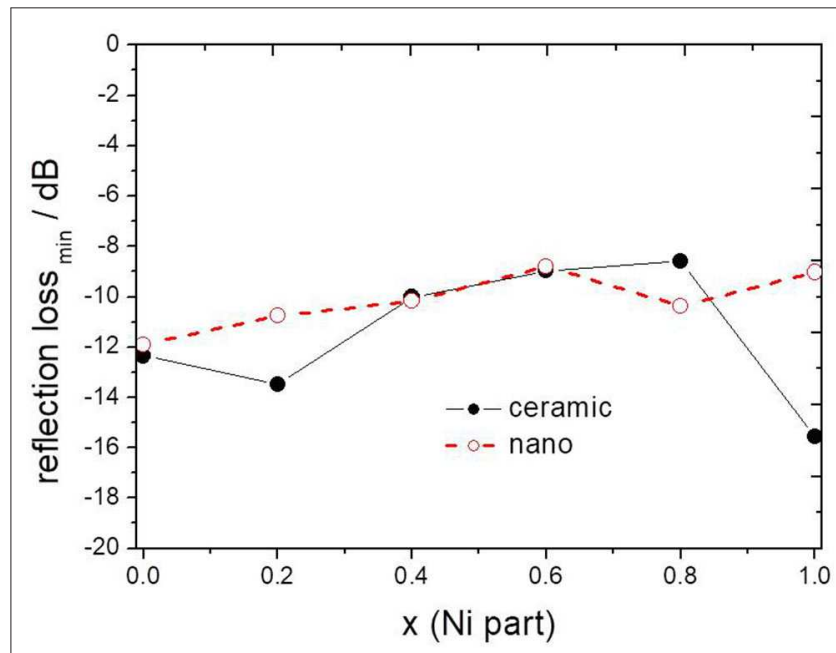

FIGURE 11 | The maximum value of attenuation depending on $\times$ (Ni content) in composite containing ceramic and nanoparticles of $\mathrm{Ni}_{x} \mathrm{Zn}_{(1-x)} \mathrm{Fe}_{2} \mathrm{O}_{4}$.

Until now, the anticorrosive properties of ferrites obtained by the ceramic method have been studied (Kalendova, 2000; Zubielewicz and Gnot, 2004; Kalendova and Vesely, 2008; Deya et al., 2010; Miszczyk and Darowicki, 2011; Hao et al., 2012; Kalendova et al., 2014; Benda and Kalendova, 2017; Chaudhry et al., 2017). In this work, a test of nano-sized ferrites was made and the obtained results were compared with the results for the same ferrites but obtained by the ceramic method, previously published (Miszczyk and Darowicki, 2011).

In order to assess the properties of nano-ferrites as corrosion inhibitors, electrochemical tests of carbon steel in 10\% aqueous extracts from nano-pigments, obtained after 2 weeks, were performed. 


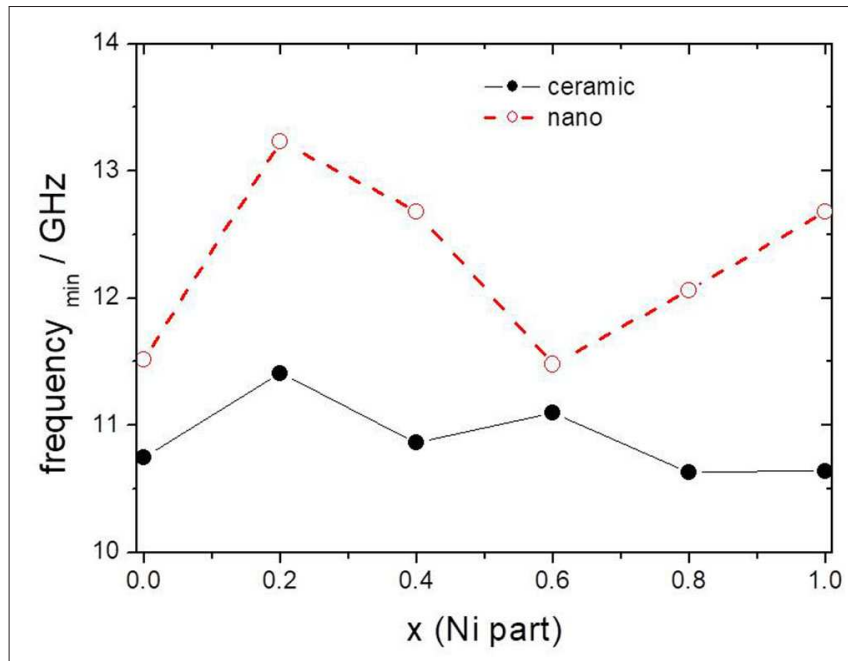

FIGURE 12 | The frequency of maximum attenuation depending on $\times(\mathrm{Ni}$ content) in composite containing ceramic and nanoparticles of $\mathrm{Ni}_{x} \mathrm{Zn}_{(1-\mathrm{x})} \mathrm{Fe}_{2} \mathrm{O}_{4}$.

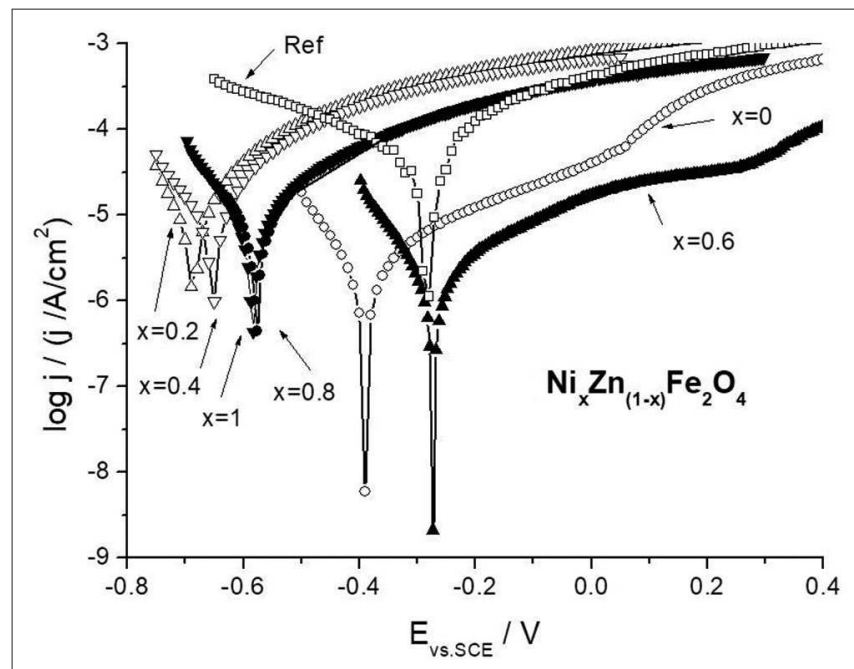

FIGURE 13 | Comparison of potentiodynamic polarization curves for carbon steel in nano-ferrite and nano- $\mathrm{Fe}_{2} \mathrm{O}_{3}$ extracts.

Figure 13 shows the polarization curves for the carbon steel samples immersed in the ferrite extracts after $1 \mathrm{~h}$ of sample immersion. There are significant differences in the electrochemical behavior of steel samples in various extracts. This indicates the activity of the studied nano-pigments in relation to the steel surface. As can be seen from the figure, the obtained polarization curves differ both in the corrosion potential and in the exchange current density from which the steel corrosion rate depends directly. The corrosion potential becomes more negative compared to the reference extract, which indicates the effect of pigments on the cathodic reaction. Also, the other slope of the cathodic portion for ferrite extracts as compared to the reference extract confirms this assumption. We observe much lower values of exchange current density, demonstrating the inhibitory effect of pigments.

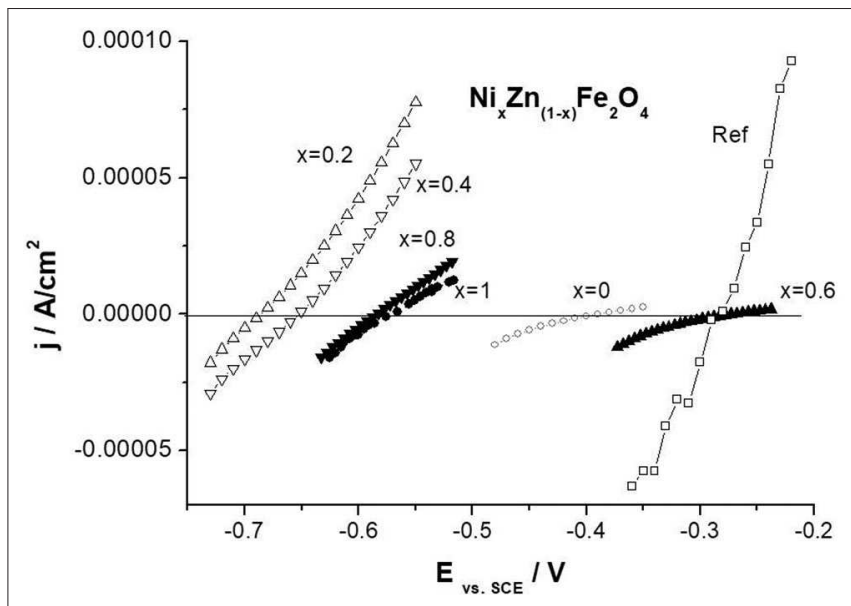

FIGURE 14 | Linear polarization plots for carbon steel in nano-ferrite and nano- $\mathrm{Fe}_{2} \mathrm{O}_{3}$ extracts.

Electrochemical studies were also performed using the linear polarization method, Figure 14. The polarization resistance was calculated from the slope of the potential vs. current density plots around the corrosion potential (using a linear portion of experimental polarization curve containing both the anodic and cathodic branches).

As a result of a carried out electrochemical measurements polarization resistances, corrosion potential and the corrosion current density for carbon steel in $\mathrm{Fe}_{2} \mathrm{O}_{3}$ and ferrite extracts were collected. Table 1 shows the results obtained. The analogous polarization resistances determined for ceramic ferrites (of micro-size) have also been presented (Miszczyk and Darowicki, 2011). In general, all ferrites with the exception of zinc ferrite show a higher polarization resistance for the nano form. This demonstrates the potentially beneficial effect of ferrites in the form of nano-size for use in protective coatings.

\section{CONCLUSIONS}

Nano-sized NiZn ferrites described by the formula $\mathrm{Ni}_{\mathrm{x}} \mathrm{Zn}_{(1-\mathrm{x})} \mathrm{Fe}_{2} \mathrm{O}_{4}$, where $x=0,0.2,0.4,0.6,0.8$, 1.0, were prepared by means of a co-precipitation method. The electrochemical behavior of carbon steel in $10 \%$ aqueous ferrite extracts was tested and compared with previous results obtained for micro-sized ceramic ferrite. The carried out tests indicate more favorable inhibiting properties of ferrites in the form of nanoparticles. An epoxy coating containing $10 \%$ vol. of obtained ferrites as a coating capable of attenuating electromagnetic radiation in the microwave range was tested. The results of coating microwave reflectivity over a range of frequencies from 6.5 to $15 \mathrm{GHz}$ were presented.

The conclusions are as follows:

1. Based on selected electrochemical tests, better anti-corrosion inhibition properties of pigments in the form of nano were found. 
TABLE 1 | The polarization resistance (in $\Omega \mathrm{cm}^{2}$ ), corrosion potential (in $V \mathrm{vs.} \mathrm{SCE)} \mathrm{and} \mathrm{the} \mathrm{corrosion} \mathrm{current} \mathrm{density} \mathrm{(in} \mu A / \mathrm{cm}^{2}$ ) of carbon steel electrode determined in $\mathrm{Fe}_{2} \mathrm{O}_{3}$ and nano-sized ferrite extracts.

\begin{tabular}{|c|c|c|c|c|c|c|c|}
\hline \multirow[t]{2}{*}{ Pigment } & \multirow[t]{2}{*}{$\mathrm{Fe}_{2} \mathrm{O}_{3}$} & \multicolumn{6}{|c|}{$\mathrm{Ni}_{x} \mathrm{Zn}_{(1-\mathrm{x})} \mathrm{Fe}_{2} \mathrm{O}_{4}$} \\
\hline & & $x=0$ & $x=0.2$ & $x=0.4$ & $x=0.6$ & $x=0.8$ & $x=1$ \\
\hline \multirow[t]{3}{*}{ Nano-sized } & 940 & 14,080 & 2,650 & 2,500 & 16,190 & 3,160 & 1,710 \\
\hline & -0.282 & -0.392 & -0.690 & -0.655 & -0.374 & -0.578 & -0.583 \\
\hline & 35.5 & 1.15 & 3.90 & 3.22 & 0.84 & 2.34 & 2.21 \\
\hline Micro-sized* & 851 & 924 & 1,343 & 1,482 & 1,752 & 1,609 & 2,893 \\
\hline
\end{tabular}

*Data comes from Miszczyk and Darowicki (2011).

For comparison, the polarization resistance for the micro-sized pigments is given in the last line.

2. Both nano- and micro-sized ferrites of the same composition embedded in epoxy matrix exhibit much the same reflection loss. For $2 \mathrm{~mm}$ thick coatings maximum attenuation on level of $8-16 \mathrm{~dB}$ was observed.

3. Nano-ferrite filled epoxy coatings exhibit higher minimum reflection frequency in comparison with ceramic-filled coatings with the same composition. A frequency shift of 1-2 $\mathrm{GHz}$ was observed.

4. Nano-ferrites obtained by co-precipitation method needed significantly lower calcining temperature, ca. $600^{\circ} \mathrm{C}$ in comparison with micro-sized ferrites obtained by traditional ceramic solid-state reaction, which demand a temperature of $1200^{\circ} \mathrm{C}$.

5. The use of AFM technique equipped with a magnetic tip enables effective observation of the presence of magnetic nano-sized particles of ferrites used as pigments in an epoxy coating.

\section{REFERENCES}

Abbas, S. M., Dixit, A. K., Chatterjee, R., and Goel, T. C. (2007). Complex permittivity, complex permeability and microwave absorption properties of ferrite-polymer composite. J. Magn. Magn. Mat. 309, 20-24. doi: 10.1016/j.jmmm.2006.06.006

Abraham, T. (1994). Economics of ceramic magnet. Am. Ceram. Soc. Bull. $73,62-73$.

Abu Ayana, Y. M., El-Sawy, S. M., and Salah, S. H. (1997). Zinc-ferrite pigment for corrosion protection. Anti-Corros. Method. M. 44, 381-388. doi: $10.1108 / 00035599710367681$

Andrade, A. L., Souza, D. M., Pereira, M. C., Fabris, J. D., and Domingues, R. Z. (2009). Magnetic properties of nanoparticles obtained by different chemical routes. J. Nanosci. Nanotechno. 9, 2081-2087. doi: 10.1166/jnn.2009.423

Armstrong, N., and Karceff, W. (1999). A maximum entropy method for determining column-length distributions from sizebroadened X-ray diffraction profiles. J. Appl. Cryst. 32, 600-613. doi: $10.1107 /$ S0021889899000692

Awschalom, D. D., and Vincenzo, D. P. D. (1995). Complex dynamics of mesoscopic magnets. Phys. Today. 48, 43-49. doi: 10.1063/1.881448

Banik, S., Bandyopadhyay, S., and Ganguly, S. (2003). Bioeffects of microwave-a brief review. Bioresource Technol. 87, 155-159. doi: 10.1016/S0960-8524(02)00169-4

Benda, P., and Kalendova, A. (2017). Development and preparation of oxide mixture-based pigments for anticorrosion paints. Pigm. Resin Technol. 46, 342-355 doi: 10.1108/PRT-01-2016-0012

Breckenkamp, J., Berg, G., and Blettner, M. (2003). Biological effects on human health due to radiofrequency/microwave exposure: a synopsis of cohort
The tested NiZn ferrites are suitable as microwave shielding and absorbing materials for potential application in the reduction of EMI. In combination with anti-corrosion properties, they might be a reasonable and cost-effective addition to modern multifunctional coatings providing additional benefits, including reduction or elimination of EMI problems.

\section{DATA AVAILABILITY STATEMENT}

The datasets generated for this study cannot be shared at this time as the data also forms part of an ongoing study.

\section{AUTHOR CONTRIBUTIONS}

AM have made a substantial, direct and intellectual contribution to this work, starting with the idea, carrying out research, working out the results, and formulating the manuscript.

studies. Radiat. Environ. Biophys. 42, 141-154. doi: 10.1007/s00411-0030203-x

Bueno, A. R., Gregorib, M. L., and Nobrega, M. C. S. (2008). Microwaveabsorbing properties of Ni0.50-xZn0.50-xMe2xFe2O4 $(\mathrm{Me}=\mathrm{Cu}, \mathrm{Mn}, \mathrm{Mg})$ ferrite-wax composite in X-band frequencies. J. Magn. Magn. Mat. 320, 864-870. doi: 10.1016/j.jmmm.2007.09.020

Chaudhry, A. U., Mittal, V., Hashmi, M. I., and Mishra, B. (2017). Evaluation of $\mathrm{Ni} 0.5 \mathrm{Zn} 0.5 \mathrm{Fe} 2 \mathrm{O} 4$ nanoparticles as anti-corrosion pigment in organic coatings for carbon steel. Anti-Corros. Method. M. 64, 644-653. doi: 10.1108/ACMM-10-2016-1725

Chaudhry, A. U., Mittal, V., and Mishra, B. (2015). Nano nickel ferrite (NiFe2O4) as anti-corrosion pigment for API 5L X-80 steel: an electrochemical study in acidic and saline media. Dyes Pigm. 118, 18-26. doi: 10.1016/j.dyepig.2015.02.023

Chen, L. F., Ong, C. K., Neo, C. P., and Varadan, V. V., Varadan, V. K. (2004). Microwave Electronics - Measurement and Materials Characterization. Chichester, UK: John Wiley \& Sons. doi: 10.1002/0470020466

Chen, Q., and Zhang, Z. J. (1998). Size-dependent superparamagnetic properties of MgFe2O4 spinel ferrite nanocrystallites. Appl. Phys. Lett. 73, 3156-3158. doi: $10.1063 / 1.122704$

Chikazumi, S. (1997). Physics of Ferromagnetism. Oxford: Clarendon Press.

Deya, C., Blustein, G., del Amo, B., Romagnoli, R. (2010). Evaluation of eco-friendly anticorrosive pigments for paints in service conditions. Prog. Org. Coat. 69, 1-6. doi: 10.1016/j.porgcoat.2010. 03.011

Dias, A., Moreira, R. L., and Mohallem, N. D. S. (1997). Sintering studies of hydrothermal NiZn ferrites. J. Phys. Chem. Solids 58, 543-549. doi: 10.1016/S0022-3697(96)00162-X 
Dosoudil, R., Usakova, M., Franek, J., Slama, J., and Olah, V. (2006). Highfrequency EMI noise suppression by polymer-based composite magnetic materials. J. Magn. Magn. Mat. 304, 755-757. doi: 10.1016/j.jmmm.2006. 02.216

Duan, Y., and Guan, H. (2017). Microwave Absorbing Materials. Singapore: Pan Stanford Publishing. doi: 10.1201/9781315364704

Ehrhardt, H., Campbell, S. J., and Hofmann, M. (2002). Structural evolution of ball-milled ZnFe2O4. J. Alloys Compd. 339, 255-260. doi: 10.1016/S0925-8388(01)02011-4

Grigoriev, D. O., Vakhitov, T., and Stepin, S. N. (2016). "Ferrites as Non-Toxic Pigments for Eco-Friendly Corrosion Protection Coatings, chap. 3," in: Biobased and Environmental Benign Coatings (Salem, MA: Scrivener Publishing; Hoboken, NJ: John Wiley \& Sons). doi: 10.1002/9781119185055.ch3

Hao, Y., Liu, F., and Han, E. (2012). Inhibitive behavior and mechanism of a ferrite inhibition pigment in epoxy paints. J. Electrochem. Soc. 159, C403-C410. doi: 10.1149/2.049209jes

Hernando, A. (1999). Magnetic properties and spin disorder in nanocrystalline materials. J. Phys.: Condens. Matter 11, 9455-9482. doi: 10.1088/0953-8984/11/48/308

Kalendova, A. (2000). Alkalising and neutralising effects of anticorrosive pigments containing $\mathrm{Zn}, \mathrm{Mg}, \mathrm{Ca}$, and Sr cations. Prog. Org. Coat. 38, 199-206. doi: 10.1016/S0300-9440(00)00103-X

Kalendova, A., and Vesely, D. (2008). The properties of $\mathrm{ZnFe} 2 \mathrm{O} 4$ as an anticorrosion pigment dependent upon the structure of initial $\mathrm{Fe}_{2} \mathrm{O}_{3}$. AntiCorros. Method. M. 55, 175-190. doi: 10.1108/00035590810887673

Kalendova, A., Vesely, D., and Kohl, M. (2014). Synthesis of Me2TiO4 and $\mathrm{MeFe} 2 \mathrm{O} 4$ spinels and their use in organic alkyd resin-based anticorrosion coatings. Corros. Rev. 32, 51-72. doi: 10.1515/corrrev-2013-0050

Kefeni, K. K., Msagati, T. A. M., and Mamba, B. B. (2017). Ferrite nanoparticles: Synthesis, characterisation and applications in electronic device. Mater. Sci. Eng. B 215, 37-55. doi: 10.1016/j.mseb.2016.11.002

Kharissova, O. V., Dias, H. V. R., and Kharisov, B. I. (2015). Magnetic adsorbents based on micro- and nano-structured materials. RSC Adv. 5, 6695-6719. doi: 10.1039/C4RA11423J

Kodama, R. H., and Berkowitz, A. E. (1999). Atomic-scale magnetic modelling of oxide nanoparticles. Phy. Rev. B 59, 6321-6336. doi: 10.1103/PhysRevB.59.6321

Koysuka, Y. (2019). Electromagnetic Wave Absorbers: Detailed Theories and Applications. Hoboken, NJ: John Wiley \& Sons. doi: 10.1002/9781119564430

Landy, N. I., Sajuyigbe, S., Mock, J. J., Smith, D. R., and Padilla, W. J. (2008). Perfect metamaterial absorber. Phys. Rev. Lett. 100:207402. doi: 10.1103/PhysRevLett.100.207402

Miszczyk, A., and Darowicki, K. (2011). Study of anticorrosion and microwave absorption properties of NiZn ferrite pigments. Anti-Corros. Method. M. 58, 13-22. doi: 10.1108/00035591111097657

Nicolaescu, I. (2006). Radar absorbing materials used for target camouflage. J. Optoelectron. Adv. M. 8, 333-338. Available online at: https://old.joam.inoe.ro/ arhiva/pdf8_1/Nicolaescu.pdf (accessed June 8, 2020).

Paniagua, J. M., Rufo, M., Jimenez, A., Antolin, A., and Sanchez, M. (2009). Electrical stimulation vs thermal effects in a complex electromagnetic environment. Sci. Total Environ. 407, 4717-4722. doi: 10.1016/j.scitotenv.2009.04.034

Poddar, A., Bhowmik, R. N., De, A., and Sen, P. (2009). Magnetic response of $\mathrm{NiFe} 2 \mathrm{O} 4$ nanoparticles in polymer matrix. J. Magn. Magn. Mat. 321, 2015-2020. doi: 10.1016/j.jmmm.2009.01.010

Pradeep, A., Priyadharsini, P., and Chandrasekaran, G. (2008). Sol-gel route of synthesis of nanoparticles of $\mathrm{MgFe} 2 \mathrm{O} 4$ and XRD, FTIR and VSM study. J. Magn. Magn. Mater. 320, 2774-2779. doi: 10.1016/j.jmmm.2008.06.012

Priyadharsinia, P., Pradeepa, A., Sambasiva Raob, P., and Chandrasekarana, G. (2009). Structural, spectroscopic and magnetic study of nanocrystalline Ni-Zn ferrites. Mater. Chem. Phys. 116, 207-213. doi: 10.1016/j.matchemphys.2009.03.011

Rana, S., Gallo, A., Srivastava, R. S., and Misra, R. D. K. (2007). On the suitability of nanocrystalline ferrites as a magnetic carrier for drug delivery: functionalization, conjugation and drug release kinetics. Acta Biomaterialia. 3, 233-242. doi: 10.1016/j.actbio.2006.10.006
Sarkar, N. N., Rewatkar, K. G., Nanoti, V. M., and Tayade, N. T. (2018). "Soft ferrite: a brief review on structural, magnetic behavior of nanosized spinel ferrites, Chap. 9," in: Magnetic Oxides and Composites (Materials Research Forum).

Sekine, I., and Kato, T. (1986). Corrosion-protective properties of various ferrite paint films. Ind. Eng. Chem. Product Res. 25, 7-10. doi: 10.1021/i300021a002

Shenoy, S. D., Joy, P. A., and Anantharaman, M. R. (2004). Effect of mechanical milling on the structural, magnetic and dielectric properties of coprecipitated ultrafine zinc ferrite. J. Magn. Magn. Mater. 269, 217-226. doi: 10.1016/S0304-8853(03)00596-1

Shi, C.h., Shao, Y., Wang, Y., Liu, B., and Meng, G. (2019). Evolutions of the protection performances of epoxy coatings containing different concentrations of submicron-sheet zinc phosphate pigment. Colloids Surf. A 577, 378-395. doi: 10.1016/j.colsurfa.2019.05.084

Shi, J., Gider, S., Babcock, K., and Awschalom, D. D. (1996). Magnetic clusters in molecular beams, metals, and semiconductors magnetic clusters in molecular beams, metals, and semiconductors. Science 271, 937-941. doi: 10.1126/science.271.5251.937

Shi, Y., Ding, J., and Yin, H. (2000). CoFe2O4 nanoparticles prepared by the mechanochemical method. J. Alloys Compd. 308, 290-295. doi: 10.1016/S0925-8388(00)00921-X

Sileo, E. E., Rotelo, R., and Jacobo, S. E. (2002). The effect of rare earth substitution on the magnetic properties of $\mathrm{Ni}_{0.5} \mathrm{Zn}_{0.5} \mathrm{M}_{\mathrm{x}} \mathrm{Fe}_{2-\mathrm{x}} \mathrm{O}_{4}$ (M: rare earth). Physica B 320, 261-263. doi: 10.1016/S0921-4526(02)00706-8

Simms, S., and Fusco, V. (2005). Thin radar absorber using an artificial magnetic ground plane. Electron. Lett. 41, 1311-1313. doi: 10.1049/el:20053236

Suarez, A., Victoria, J., Torres, J., Martinez, P. A., Alcarria, A., Martos, J., et al. (2019). Effectiveness assessment of a nanocrystalline sleeve ferrite core compared with ceramic cores for reducing conducted EMI. Electronics (MDPI) 8:800. doi: 10.3390/electronics 8070800

Vermaa, V., Pandeya, V., Singha, S., Aloysiusa, R. P., Annapoornib, S., and Kotanalaa, R. K. (2009). Comparative study of structural and magnetic properties of nano-crystalline $\mathrm{Li}_{0.5} \mathrm{Fe}_{2.5} \mathrm{O}_{4}$ prepared by various methods. Physica B 404, 2309-2314. doi: 10.1016/j.physb.2009.04.034

Vinas, S. L., Simeonidis, K., Li, Z. A., Ma, Z., Myrovali, E., Makridis, A., et al. (2015). Tuning the magnetism of ferrite nanoparticles. J. Magn. Magn. Mat. 415, 20-23. doi: 10.1016/j.jmmm.2016.02.098

Vinoy, K. J., and Jha, R. M. (1996). Radar Absorbing Materials: From Theory to Design and Characterization. Boston: Kluwer Academic Publishers.

Wang, B., Koschny, T., and Soukoulis, C. M. (2009). Wide-angle and polarization-independent chiral metamaterial absorber. Phys. Rev. B 80, 033108. doi: 10.1103/PhysRevB.80.033108

Weston, D. A. (2001). Electromagnetic Compatibility, Principles and Applications. $2^{\text {nd }}$ ed. Basel; New York, NY: Marcel Dekker.

Yusoffa, A. N., and Abdullah, M. H. (2004). Microwave electromagnetic and absorption properties of some LiZn ferrites. J. Magn. Magn. Mat. 269, 271-280. doi: 10.1016/S0304-8853(03)00617-6

Zeddam, A., Gautier, A., and Tlich, M. (2009). Electromagnetic environment and telecommunications: towards a cognitive electromagnetic compatibility. C.R. Physique 10, 4-12. doi: 10.1016/j.crhy.2009.02.001

Zhao, D. L., Zeng, Q. L., and Shen, M. (2009). Fabrication and microwave absorbing properties of Ni-Zn spinel ferrites. J. Alloys Compd. 480, 634-638. doi: 10.1016/j.jallcom.2009.01.130

Zubielewicz, M., and Gnot, W. (2004). Mechanisms of non-toxic anticorrosive pigments in organic waterborne coatings. Prog. Org. Coat. 49, 358-371. doi: 10.1016/j.porgcoat.2003.11.001

Conflict of Interest: The author declares that the research was conducted in the absence of any commercial or financial relationships that could be construed as a potential conflict of interest.

Copyright (c) 2020 Miszczyk. This is an open-access article distributed under the terms of the Creative Commons Attribution License (CC BY). The use, distribution or reproduction in other forums is permitted, provided the original author(s) and the copyright owner(s) are credited and that the original publication in this journal is cited, in accordance with accepted academic practice. No use, distribution or reproduction is permitted which does not comply with these terms. 